\title{
PROBABLE CASE OF DEATH-FEIGNING BY WOOD FROG
}

ROBERT KREBA, \#4-2805 Parliament Avenue, Regina, Saskatchewan S4R 2L1

While exploring a wooded swamplike area in the back slope zone of the sand dunes at Good Spirit Lake Provincial Park (1400, May 21, 1977), I encountered several wood frogs, Rana sylvatica. I collected one specimen, intending to photograph and later release it. It was put in a ventilated jar with just enough water to keep it moist.

About an hour later, I looked at the frog and was surprised to see that it appeared dead. I removed it from the jar and examined it briefly. The legs were limp, outstretched away from the body, eyes half-closed, and no breathing could be discerned. I held it losely for about two minutes, and it did not stir or attempt to escape; when captured it had seemed vigorous and healthy. It showed no sign of emaciation or disease, yet was, inexplicably, apparently dead. It was about $35 \mathrm{~mm}$ in body length, and of undetermined sex.

I decided to at least return the dead amphibian to its natural habitat, and walked a short distance to a small slough, also in the wooded area. I tossed in the "corpse", and to my surprise it immediately swam away.

There have been previous reports of death-feigning amphibians both in volving the Canadian Toad, Buf hemiophrys ${ }^{12}$. Although thi behaviour has also been recorded fo several other amphibian species, has not, to my knowledge, bee previously recorded for $R$. sylvatica.

It is generally accepted that death feigning is employed as a predator es cape device. McNicholl ${ }^{1}$ cites obser vations concerning the unwillingnes of tiger salamanders, Ambystom tigrinum, to take unmoving food $c$ prey, which at times includes frog and toads. My own observations ove the years, with captive tigc salamanders, and several species $c$ native snakes, as well as exotic snake agree with his observations. It woul seem that many amphibians and rep tiles are incapable of recognizing a organism as potential prey unless moves. Death-feigning in the woo frog would appear to be of definit advantage as protection again animal as well as human predators.

${ }^{1}$ MCNICHOLL, M. K. 1972. An observatic of Apparent Death-feigning by a Toa Blue Jay 30:54-55.

${ }^{2}$ NERO, R. W. 1967. A Possible Record Death-feigning in a Toad. Blue 25:193-194.

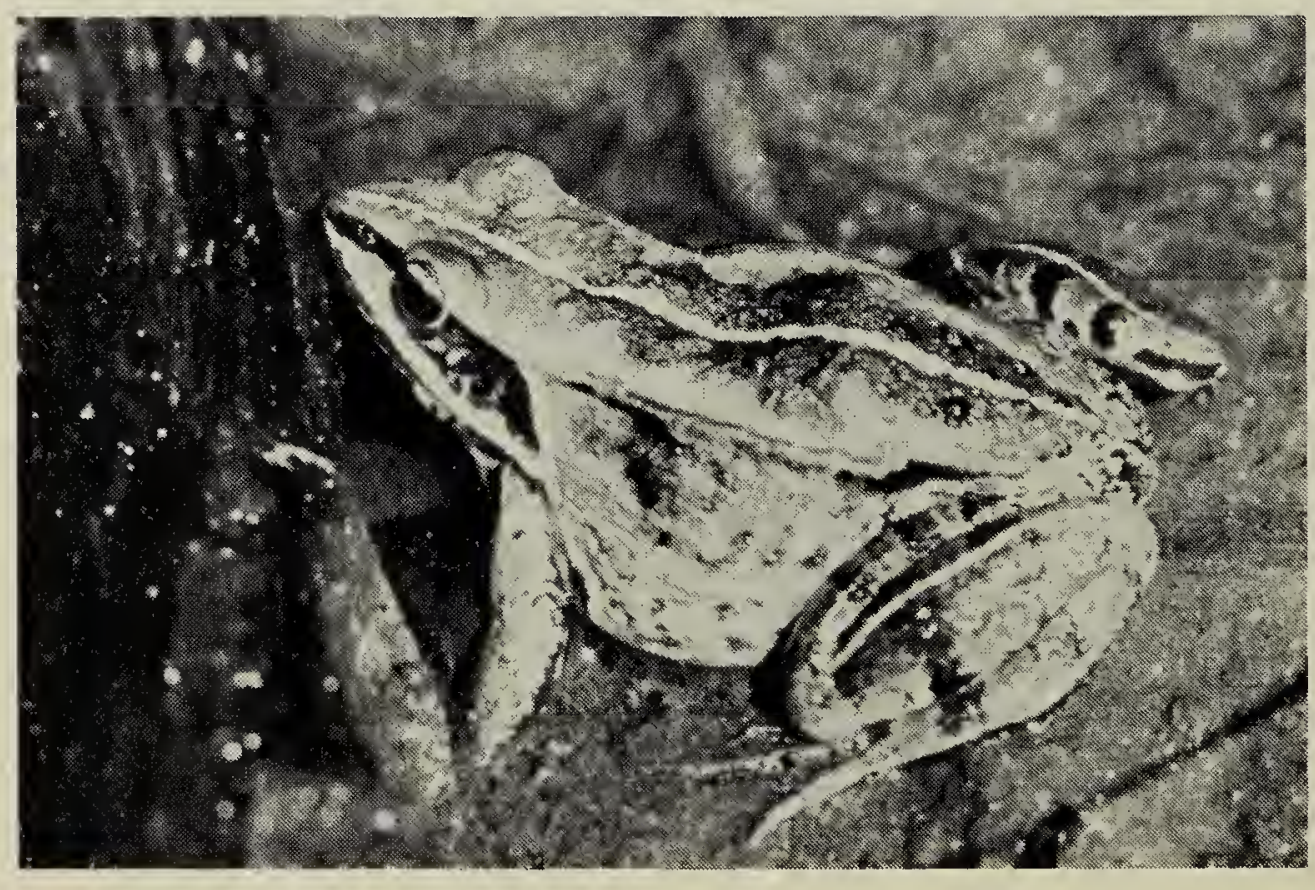

Wood Frog

Gary W. Se 